Behavior and Social Issues, 26, 128-155 (2017). (C) Deric E. Toney \& Linda J. Hayes. Readers of this article may copy it without the copyright owner's permission, if the author and publisher are acknowledged in the copy and the copy is used for educational, not-for-profit purposes. doi: 10.5210/bsi.v.26i0.7425

\title{
A BeHAVioral ANALYSis of APOlOgies, Forgiveness, AND INTERPERSONAL CONFLICT
}

\author{
Deric E. Toney and Linda J. Hayes ${ }^{1}$ \\ University of Nevada, Reno
}

\begin{abstract}
Episodes of conflict can be among the most distressful experiences while interacting with others or within a relationship. There are a number of behaviors that occur to compose a conflict, however there are two behaviors that serve to restore a relationship following a conflict, those of apologizing and forgiving. While substantial attention has been provided to the issues of interpersonal conflict, apologizing, and forgiving from more traditional approaches, these accounts contrast with the views of behavior analysis in a number of ways. When the behaviors involved in interpersonal conflict are assessed from a behavioranalytic perspective, many of these traditional views are directly challenged. Furthermore, we find that the manner in which conflicts are normally resolved within relationships may be contributing to harmful patterns of interacting. The present paper aims to provide a thorough behavioral analysis of the operating contingencies and behaviors that occur during episodes of interpersonal conflict. With such an understanding, suggestions are made based on behavioral principles and procedures as to how resolution may be more readily achieved and further conflict may be avoided.
\end{abstract}

KEYWORDS: conflict, apology, forgiveness, relationships, behavior analysis

Relationships of every kind can be complicated and at times difficult for the individuals involved. While the majority of interactions within a relationship ideally are positive, it is almost unavoidable to experience a conflict of some sort. Individuals disagree, argue, insult, or cause pain to the other, all of which are likely distressing to those involved. These interactions can result in an array of unpleasant circumstances, such as avoidance, retaliation, or even the termination of a relationship. However, the behaviors of apologizing and forgiving serve to restore the relationship following a conflict; therefore, an examination seems warranted.

The behaviors of apologizing and forgiving have become common features of our repertoires. The types of situations in which we engage in one or the other can vary greatly, such as when we abruptly walk in front of an individual at a grocery store to more substantial offenses as when a leader apologizes to a nation for wrongful action in war. These behaviors also occur across various types of relationships; a parent demands her child apologize to a sibling, and a partner proclaims to a spouse, "I deserve an apology." Being such common behaviors, apologizing and forgiving have received a great deal of attention from traditional fields. However, these accounts pose an array of differences when compared to those of behavior analysis. These differences, in general, pertain to the treatments of emotion, the emphasis on the form rather than the function of the responses involved, and the treatment of one independent individual's behavior.

\footnotetext{
${ }^{1}$ Authors may be contacted at dtone01@gmail.com (Toney) or lhayes@unr.edu (Hayes).
} 


\section{APOLOGIES, FORGIVENESS, AND INTERPERSONAL CONFLICT}

A particular difficulty for behavior analysts in addressing issues of apologies and forgiveness is that in traditional treatments, those concepts are heavily rooted in emotions such as regret, guilt, anger, shame, etc. (e.g., Chapman \& Thomas, 2006; Kador, 2009; Lazare, 2004). The language surrounding emotions in these accounts suggest or imply that they are the cause $e^{2}$ of the behaviors that occur during a conflict (see Hareli \& Eisikovits, 2006; Mushkambaryan, 2012; Retzinger, 1991). However, from a behavior-analytic perspective, emotions are not considered to be causally related to the overt behaviors they accompany, but instead to be collateral, covert responses that operate under the same contingencies (Skinner, 1953, 1974, 1975).

There are certainly covert forms of stimulation and responding present in episodes of conflict, as some forms of covert stimulation and responding are present in all behavioral events. Behavior analysis has not ignored these features of behavioral events. In fact, the roles of emotions in overt behavior have been discussed in many fashions such as interactions of operant and respondent forms of responding (Catania, 2007), motivational variables (Lewon \& Hayes, 2014), and descriptions of changes in contingencies (Layng, 2017). However, behavior analysis' general focus on publically observable events rather than unobservable events, such as emotions, leads to quite a different analysis of conflict than other approaches. The reliance on emotions in analyses of conflict directs attention away from what is seen to be the critical concern in conflict from this perspective, which is behavior change. The focus, then, is not to address or relieve the emotions of the individuals involved, but instead to modify the social or environmental conditions related to the behaviors that gave rise to the conflict and those that might lead to the resolution.

Traditional accounts also emphasize the topography or form of the responses involved, such as the statements, words, or actions included in the apology (e.g., Kador, 2009; Simpson, 2005). Behavior analysis takes a different approach to assessing verbal interactions, placing a greater emphasis on the functions of the behaviors that occur (Skinner, 1957). Although the form of these behaviors does play an important role in how a conflict unfolds, particularly regarding their discriminative functions, concentrating on form alone does not allow for a causal analysis (Skinner, 1953, 1957). By focusing solely on the form of a response, an analysis is limited to an individual occurrence; while responses that vary in form yet serve the same function (i.e., an operant) may be inadequately assessed, which also hinders our ability to predict a particular occurrence. On the other hand, addressing behaviors in terms of response classes and operants allows for us to understand and predict under which conditions a response that serves a particular function might occur whereby appropriate modifications to those environmental conditions may be achieved.

Lastly, traditional treatments tend to address the behavior of only one of the individuals involved in the interaction such as the behavior of the victim (e.g., McCullough, Bellah, Kilpatrick, \& Johnson, 2001), or the behavior of the offender (e.g., Witvliet, Ludwig, \& Bauer, 2002). While these works are undoubtedly valuable in our understanding of conflict, by its very nature, interpersonal conflict cannot exist with one independent individual. It is the engagement of at least two persons that produces a conflict; therefore, an analysis of both individuals' behavior and how each affects the other's behavior is necessary for a thorough understanding. Furthermore, through assessing both individuals' behavior, the use of concepts such as blame, fault, and responsibility, which are used commonly in describing actions in conflict, is challenged. The use of such concepts reveals an effort to isolate the cause of the conflict in one person's actions, and in so doing we

\footnotetext{
${ }^{2}$ Skinner (1978) discussed this tendency of contributing a causal role to emotions as a result of having difficulty in locating the appropriate source of control for the behavior.
} 


\section{TONEY \& HAYES}

overlook the importance of both individuals' actions that were required to produce the conflict. According to Skinner (1957), a complete explanation of verbal interactions requires separate but interlocking accounts of the behaviors of the speaker and the listener (p. 34). Therefore, a comprehensive analysis of a verbal episode must consider the discriminative and consequential effects of each individual's behavior upon the other's behavior and assess how these variables affect interactions over time.

Depending on a number of variables, interpersonal conflict can unfold in a variety of ways. Some forms of interaction during conflict may improve resolution and the functioning of the relationship, while other forms may hinder resolution and worsen conditions for the individuals involved. With the aim of improving behavior in a socially significant way, behavior analysis offers a beneficial approach to understanding these interactions. Therefore, the purpose of the present paper is to illustrate the basic behavioral principles and contingencies present in episodes of interpersonal conflict. Since the specific variables present in episodes of conflict vary widely, accounting for all possible types of interactions and their relevant variables is beyond the scope of the present paper. Rather common examples of episodes of interpersonal conflict will be used to guide the analysis, with an understanding that particular episodes of conflict might unfold differently than how they are presented here. Finally, based on both basic and applied behavioral research, suggestions are then provided by which conflict might be avoided, resolution may be more readily achieved, and the overall quality of interactions within a relationship may be more positive for both individuals.

\section{The Offender's Aversive Behavior}

Before delving into complex forms of verbal interactions from a behavior-analytic perspective, a few general points should be made. First, the stimulus functions and motivational variables present in episodes of interpersonal conflict for those involved are products of each individual's separate histories, both outside of the relationship and that which has been shared within the relationship. The effects of individual histories cannot be overstated; a position widely held and understood in behavior analysis. Second, since verbal interactions as they occur within conflict can be temporally distant to one another, many of the responses that serve as consequences to others may be considered to be part of analog contingencies compared to direct-acting contingencies (see Malott and Shane, 2016). We refer readers to Hayes (2004) and Malott and Shane (2016) for further discussions on this distinction.

In any verbal episode involving two persons, both persons participate in the roles of speaker and listener. The speaker's behavior serves a dual function of both an $\mathrm{S}^{\mathrm{D}}$ for subsequent behavior and a consequence for preceding behavior on the part of the listener. Since the roles of speaker and listener continuously alternate throughout prolonged verbal interaction, in the following account, the actors in the interaction rather than their roles of speaker and listener will be addressed. In accordance with traditional treatments on the matter, the actors that are involved in conflict will be referred to as the victim and the offender.

A conflict will be treated as an episode that begins with an offender's aversive behavior, which is one the victim responds to as if it were hurtful, offensive, rude, disrespectful, painful, and so on. There are a number of behaviors that are commonly referred to as such like insults, lying, infidelity, injustices, betrayal, damaging one's property, or annoyances. The victim responds in such a way as to escape, terminate, and/or reduce the probability of such behaviors occurring again; therefore, behavior from the offender that produces such an effect will be described as aversive. 
The term aversive is applied to stimuli whose reduction or termination has a reinforcing effect upon the behavior that produced these changes (Dinsmoor, 1954). In cases of conflict, products of behaviors are not considered aversive based on their formal characteristics or the feelings they may invoke upon the victim, but rather the effects they have on the victim's behavior. Depending on a number of historical variables, the products ${ }^{3}$ of behaviors that one person may respond to as if they were aversive can be quite different from those of another person or under divergent circumstances. This means that no behavior is inherently hurtful, offensive, or rude until a listener responds to it as such (see Kowalski, 2001).

Although it is the victim's response to these behaviors that illustrates their aversive function, there are behavioral features and/or aspects of the interaction that might contribute to this effect. To provide an illustration of some of these features, the following will be discussed: (1) relationship-specific contingencies, (2) situational variables, (3) frequency, (4) nonverbal and paralinguistic features, (5) physical pain, and (6) behavioral deficits and failures to respond.

1. Relationship-specific contingencies. Within each relationship, contingencies develop surrounding particular classes of behaviors. These contingencies can be viewed as rules of conduct within the relationship wherein certain behaviors under particular conditions are reinforced and other behaviors may be aversive and punished. Aversive behaviors are typically different in form than those behaviors that are part of the existing reinforcement contingencies of the relationship. However, these contingencies are unique across relationships and the same response can have a different effect depending on the relationship. For example, a friend may criticize a person's outfit and this may not be aversive; however, it would be aversive if his or her significant other made the same criticism. $^{4}$

2. Situational variables. There are also situational variables at the time of occurrence that affect the aversive functions of a behavior. A behavior might be aversive under one set of circumstances, yet reinforced under others. Suppose an individual regularly requests that his or her partner prepare some food; if the present circumstances are such that the partner is busy with other matters, he or she may respond as if this request was aversive. This is not due to the form of the request but rather the conditions that are present at the time of its occurrence. ${ }^{5}$ Events that occur outside of the relationship may contribute to this effect as well. If a person recently failed an exam and a friend made an insensitive joke, the person will likely respond as if this joke was aversive. Even if this type of joking was usually reinforced within the friendship, the event of failing the exam might produce motivational effects to respond to the joke differently. The variables that affect the aversive functions of a behavior may also change over time within the relationship. At the start of a relationship, some behaviors may not be aversive but as conditions change, so does what the victim responds to as aversive. A person might purchase items

\footnotetext{
${ }^{3}$ It is understood that listeners respond to the response products of a speaker's behavior and not the behavior itself. For the sake of brevity, this detail will be omitted throughout the remainder of the discussion.

${ }^{4}$ See Skinner (1957, pp. 230-231) for a related discussion on the effects of multiple audiences in which some listeners may reinforce certain responses whereas others might punish.

${ }^{5}$ See Skinner (1953, p. 299) for a discussion on how the contingencies for social behavior vary constantly. Depending on the condition of the listener, a response may produce different consequences.
} 


\section{TONEY \& HAYES}

frivolously in the earlier stages of a relationship, but as finances become a more central part of the relationship, this type of spending could be aversive for the victim.

3. Frequency. The frequency of a behavior can also attribute to its aversive functions for the victim. Here, a single occurrence of a behavior may not prove to be aversive, but after repeated occurrences, the victim may come to respond to these later occurrences as if they were aversive, much like the effects of sensitization (see Groves \& Thompson, 1970). A person may call his or her partner routinely, however if he or she frequently calls in a short amount of time, this may prove to be aversive, and the victim may answer the call somewhat aggressively, such as, "I can't talk right now!"

4. Nonverbal behaviors and paralinguistic features. Nonverbal features of behavior may also produce aversive effects. Such behaviors can accompany verbal behaviors and contribute to their aversive functions, such as a when a person witnesses another person struggling with a task and then stating with a smirk, "Maybe you should let me try." Nonverbal behaviors that carry an aversive function can also occur independent of verbal behaviors, like when a colleague rolls his or her eyes when a coworker boasts about a promotion. Additionally, paralinguistic features of verbal behaviors such as the vocal tone, volume, inflection, and rapidity of the behavior may all contribute to its aversive functions. This can be observed in conflict situations in which a person says, "I am not mad about what you said. I am mad about how you said it." Imagine a person runs into a friend at a party, and the friend says, "I didn't expect to see you here," versus saying, "I didn't expect to see you here." The change in inflection and stress on the words "you" versus "see" may produce variable responses from the victim. Or if a person sees a friend after a long period of time and says, "You look great!" instead of, "You look...great!"

5. Physical pain. A distinction should be made between aversive behaviors of a verbal form and those of a nonverbal form that produce physical pain, such as stepping on a person's toes. Some have stated that aversive interpersonal verbal events can be comparable, if not more significant, than events that cause physical pain or injury (e.g., Leary, Springer, Negel, Ansell, \& Evans, 1998). While both types of events may serve aversive functions for the victim, the response that occurs will likely be quite different. This is potentially due to the conditioning involved in verbal responses whereas the response to physical pain may be partly reflexive in nature (see Azrin, Hutchinson, \& Sallery, 1964; Berkowitz, 1983; Ulrich \& Azrin, 1962).

6. Behavioral deficits and failures to respond. Behavioral deficits, such as an unsatisfactory frequency of a particular behavior of the offender or instances in which an offender fails to comply with a command or traditionally speaking, failure to meet expectations, may also result in the victim responding as if the event were aversive. For example, a victim may respond as if it were aversive that a close friend failed to call on his or her birthday. Although failing to engage in a behavior is not a behavioral event, following certain events (i.e., a person stating that they will be in attendance and then failing to show, a person telling a partner that he or she would complete a chore and then failing to do so, etc.) the victim may respond to the circumstance in a manner similar to the features listed above.

While there are many variables that may contribute to the victim's response to a behavior as if it were aversive, ultimately the functions of these response features are acquired through a 
history of reinforcement. As mentioned above, the aversive functions of a behavior are not an inherent property of the behavior; these effects are only illustrated in the victim's response to the behavior.

\section{The Aversive Behavior as a Discriminative Stimulus}

In assessing the discriminative functions of the aversive behavior, a distinction should be made between the victim's response to the possible effects an aversive behavior had on the physical environment compared to the effects on the social environment. Regarding conflict, it is the latter response that is of concern and that which will be discussed. For example, if a child broke a mother's vase, the response of concern is not the mother's discovery of the broken vase, but instead her subsequent response to the child.

Given the aversive functions of this behavior, the victim is likely to respond in rather predictable ways. First, the aversive behavior might serve a discriminative function over constructive responses from the victim that operate to produce more desirable behavior from the offender under similar conditions as the aversive behavior. These behaviors are referred to as conflict assertive behaviors (Rakos, 1991) and will be discussed in more detail later. Second, the victim is also likely to engage in a number of responses that serve to terminate the aversive behavior and/or escape the offender. These responses of the victim are referred to as offended responses.

\section{The Victim's Offended Response}

\section{The Offended Response as a Method of Punishment}

The victim's offended response serves as a consequence that punishes the offender's aversive behavior. There are generally two types ${ }^{6}$ of offended responses that produce this effect, which will be referred to as aggressive and withdrawal offended responses (see a related discussion in Marchand \& Hock, 2000). Aggressive offended responses (AORs) are those that carry an aversive function for the offender and commonly take the form of yelling, complaining, insulting, threats, physical aggression, and so on. As they occur in the presence of aversive behaviors, these responses hold many similarities with pain-induced aggressive responses (see Berkowitz, 1983, 1993; Ulrich \& Azrin, 1962; Ulrich, Hutchinson, \& Azrin, 1965). Given that these responses produce a reduction in aversive behaviors, their effects would be considered that of positive punishment.

Withdrawal offended responses (WORs) are a form of the victim's escape or avoidance behavior following an offender's aversive behavior. Contingent upon the aversive behavior, the victim either refrains from interacting with the offender entirely, or he or she may continue to interact although no longer in a manner that reinforces the offender's behavior. This avoidance includes refraining from interacting while in the same space, such as no longer having pleasant conversations or engaging in enjoyable activities, or instances in which the victim is spatially distant from the offender and actively engages in responses to avoid interaction, such as ignoring phone calls or texts. If the removal of such reinforcing responses produces a reduction in the

\footnotetext{
${ }^{6}$ Similarly, McCullough, Rachal, Sandage, Worthington, Brown, Hight, (1998) discuss a two-component motivational system that describes, following an offense, the victim experiences feelings of (a) hurt that lead to avoidance and (b) feelings to seek revenge or see harm to the offender.
} 


\section{TONEY \& HAYES}

offender's aversive behavior, WORs serve as a form of negative punishment. While the function of the victim escaping the offender may present as a form of negative reinforcement for the victim's behavior; this action might simultaneously produce a reductive effect on the offender's behavior that occasioned it. Meaning, in not all circumstances of WORs is the victim intending to punish behavior but instead to escape aversive stimuli; however, it may produce these punishing effects nonetheless.

There are additional features of both types of offended responses that produce variable effects that should be considered. Since AORs are a form of positive punishment, their intensity may be related to their reductive effects upon the aversive behavior. It has been observed that aversive stimuli of mild intensity result in moderate reductions of the responses they follow, while those of severe intensity produce more substantial reductions (e.g., Appel, 1963; Azrin, 1960; Boroczi, Storms, \& Broen, 1964; Filby \& Appel, 1966; Johnston, 1972). As such, the greater the intensity of the offended response (i.e., screaming, insults, threats, etc.), the greater may be its reductive effect on the frequency of aversive behaviors. However, there are potential risks that arise with greater intensities of aversive stimuli.

Numerous studies have shown that aversive stimulation produces aggression (e.g., Ulrich \& Azrin, 1962) and that the greater the intensity of aversive stimuli, the higher the rate of aggressive responses (Vernon \& Ulrich, 1966). Likewise, intense forms of AORs may result in the offender retaliating and aggressing towards the victim. Similarly, aversive stimuli of greater intensities have also shown to produce higher rates of avoidance and escape (Boren, Sidman, \& Herrnstein, 1959), meaning that the offender may come to avoid the victim following more intense AORs. Given these possibilities, a victim may be likely to engage in an AOR of enough intensity to reduce the frequency of aversive behaviors, though of insufficient intensity to produce unwanted responses from the offender.

Extinction from the offender of appropriate responses to aversive behavior or mild intensity AORs might produce an increase in intensity as well. If the victim engages in a mild AOR and the offender extinguishes this through failing to apologize or modifying his or her behavior accordingly, an increase in the intensity of the AOR may occur as is typically observed in instances of extinction (e.g., Azrin, Hutchinson, \& Hake, 1966; Kelly \& Hake, 1970). Imagine an instance where a victim states, "Well, I do not like the way you said that." This may be considered a mild AOR, but in the event the offender fails to engage in an apology, the victim will likely increase the intensity of the AOR such as increasing the volume of his or her voice, changing facial expression and stating, "You never take me seriously!"

As for WORs, their duration should be considered. It has been found that greater durations of negative punishment (i.e., time-out) produce greater reductive effects upon behavior when compared to shorter durations (e.g., White, Nielsen, \& Johnson, 1972). It is possible that the longer the duration of the WOR, the greater the reduction in the aversive behavior will be observed. Inversely, WORs that are of a brief duration will likely have minimal punishing effects upon aversive behaviors. Of course, within interpersonal relations, this effect may be more variable than that which occurs in controlled studies.

For each type of offended response, its reductive effects on the aversive behavior are also likely related to the probability of its occurrence following aversive behaviors or the schedule in which they occur. It has been shown that the schedules in which punishing stimuli are delivered are directly related to the reduction in the targeted response (e.g., Clark, Rowbury, Baer, \& Baer, 1973; Lerman, Iwata, Shore, \& DeLeon, 1997; Thomas, 1968). Meaning, in cases in which the victim occasionally responds to an aversive behavior with an offended response, the aversive 
behavior may continue to occur more so than in cases in which the victim responds consistently to the aversive behavior in such a way.

The immediacy of the offended response following the aversive behavior, or latency, may also contribute to its punishing effects. Research has shown that the more immediate the delivery of a punishing stimulus, the greater its reductive effects (Abramowitz \& O'Leary, 1990; Banks \& Vogel-Sprott, 1965). Instances in which the offended response occurs with a greater latency following the aversive behavior, the smaller a reduction in the aversive behavior might be observed. Certainly, it is common that there are somewhat significant latencies between offended responses and aversive behaviors and even with a delayed occurrence; these offended responses can effectively reduce aversive behaviors. In these instances, analog contingencies are at play, and their effectiveness is likely attributed to some form of rule governance.

\section{The Offended Response as a Discriminative Stimulus}

Characteristic of punishing stimuli, there are a number of discriminative functions (see Johnston, 1972) that may result in the offender responding to the offended response in different ways. First, particularly in the presence of AORs, the offender might escape from the victim or respond in aggressive manners, as mentioned above. These aggressive responses will be referred to as defense responses, which operate similarly to offended responses but from the offender's perspective. These responses are a form of counter-control (Sidman, 1989; Skinner, 1953, 1971) and they serve to terminate or punish the offended response. Defense responses may take the form of the offender denying fault, justifying actions, turning the tables (i.e., tu quoque), competing with the victim, etc. Consider a situation where a person noticed his or her partner purchased the wrong type of milk from the grocery as was requested. The person yells, "You picked up the wrong type of milk?" and the spouse responds with, "Well, you forgot to change the laundry!" The contingencies have now been altered and become unrelated to the initial aversive behavior; therefore, the resolution will likely be delayed, and the overall duration of the conflict is extended. This is due to the simultaneous escalation of the responses of both individuals, which may be attributed to schedule effects (i.e., responses that are on extinction within intermittent schedules of reinforcement) and a concurrent delay to reinforcement (see Hantula, 1992).

There are also nonverbal behaviors or features of offended responses that may acquire discriminative functions over the offender's behavior. In the case of AORs, there are changes in voice volume, facial expressions, and/or changes in body positioning that may have become correlated with an escalation in the response form. If these behaviors exert control over the offender's behavior, they may serve as a form of warning stimuli that commonly operate within avoidance contingencies (see Dinsmoor, 1954; Michael, 2000; Sidman \& Boren, 1957; Ulrich, Holz, \& Azrin, 1964).

Often, AORs and WORs occur within a chain wherein an AOR precedes a WOR in which the victim terminates the interaction and escapes the situation. In other circumstances in which the victim engages in a WOR, the victim engages in some behavior that has reliably preceded the termination of interaction that is not an AOR. The victim might make a statement like, "Alright. I am done with this conversation," immediately before hanging up the phone, or picking up one's belongings like keys or a purse before exiting an interaction. The products of these types of behaviors may exert control over the offender's behavior that operates to avoid the loss of interaction, similarly to stimuli operating within an avoidance of loss contingency (see Malott \& Shane, 2016). For both types of warning stimuli (those that precede escalation in AORs or are 


\section{TONEY \& HAYES}

followed by escape in WORs), they may have discriminative functions for responses of the offender that operate to de-escalate the responses or prevent the worsening of conditions.

Not all offended responses operate as forms of punishment. In the presence of behavioral deficits, the offended response serves a discriminative function over the behavior that was predicted to occur under a set of conditions, yet it did not occur. The offended response in these circumstances differs from those discussed above as its function is not to reduce or terminate the presence of an aversive behavior, but instead to coerce the offender to engage in a particular behavior (see Sidman, 1989). Perhaps in many instances in which the victim stated a rule for the occurrence of a particular behavior and the offender failed to comply, these offended responses occur due to the effects of extinction of the rule presented.

The array of response forms over which these features of the offended response exert control is vast. However, in the presence of offended responses, the offender's responses that operate to terminate aversive forms of responding, avoid the potential worsening of conditions, and/or produce more reinforcing behavior from the victim are commonly referred to as an apology.

\section{The Offender's Apologetic Response}

The offender's apologetic response is defined by its function in terms of its effect on the victim's forgiving response. There are multiple response forms, including those that are nonverbal ${ }^{7}$ (i.e., giving the victim a hug, presenting gifts, performing thoughtful acts, etc.) and those that are verbal $^{8}$ (i.e., saying, "I'm sorry," promising to change behavior, etc.) that commonly have this effect. As with the victim's offended response, the offender's apologetic response serves as a consequence for the offended response as well as an $\mathrm{S}^{\mathrm{D}}$ for subsequent behavior on the part of the victim and each will be discussed.

\section{The Apology as a Consequence}

In the event that the offender apologizes, the apologetic response operates as the consequence for the offended response, and it likely has an effect on the offended response's future probability. In most cases, this effect is that of reinforcement, and as such, an increase in the frequency of the victim's offended responses should be expected. However, the offended response punishes the aversive behavior that occasioned it. As a result of these punishing effects, a decrease in the frequency in aversive behavior might occur, and therefore a decrease in the $S^{\mathrm{D}}$ for the offended response simultaneously occurs. This means that although the offended response is reinforced by the apologetic response, an increase in its frequency might not occur due to a concurrent reduction in the opportunity to engage in the response.

This effect pertains to the particular relation between a specific aversive behavior and a specific offended response. Although, as result of being reinforced, variable forms of the offended response may be likely to occur under similar conditions as a result of response and stimulus generalization (see discussion in Shepard, 1958). For example, a friend's apology reinforces a victim's offended response, and while that particular offended response may not occur again

\footnotetext{
${ }^{7}$ See Kazdin \& Klock (1973) for an applied example of how the products of nonverbal behaviors are capable of functioning as reinforcers.

${ }^{8}$ These nonverbal and verbal forms can occur simultaneously or as part of a chain and the nonverbal features may significantly affect the manner in which individuals respond to verbal content (see Noller, 1980).
} 
within that relationship, the victim is more likely to engage in an offended response under similar conditions or perhaps with another friend due to this history of reinforcement.

An additional effect of reinforcement is that of selection (Skinner, 1981). In this case, the offender's apology selects the form of the offended response that preceded it. Many features of offended responses were discussed above, and the occurrence of these features in the presence of aversive behaviors is a product of a history of reinforcement provided by the offender's apologetic response. If a spouse engages in frequent AORs, it is likely the case that he or she has an extensive history in which responding as such has produced apologetic responses under similar conditions. This is particularly an issue in circumstances in which the offender apologizes in the presence of higher intensity AORs; it is likely that variable forms of such intense responses will occur again.

\section{The Function of the Apology}

The apology serves to ameliorate the effects of the offended response and therefore has an inverse function in relation to the type of offended response (aggressive or withdrawal) that occurred. Due to their aversive properties, AORs establish a negative reinforcement contingency for the offender, and the apologetic response serves to terminate such forms of the victim's responding or to avoid the potential worsening of conditions to follow (e.g., Darby \& Schlenker, 1982; Ohbuchi, Kameda, \& Agarie, 1989). Examples of this can be observed in apologetic responses from an employee to a supervisor to avoid getting fired, from a child to a parent to avoid getting grounded, or from a convicted criminal to a judge to avoid a harsher prison sentence.

An additional negative reinforcement function of apologies that occurs in the presence of AORs is that of de-escalation. Apologies that occur in the presence of warning stimuli described above may prevent the increase in the intensity of the victim's behavior. These warning stimuli occur as a form of precursor behavior to more intense AORs. Apologizing in the presence of these responses of the victim may be similar to the clinical practice of intervening at the precursor (see Dracobly \& Smith, 2012; Najdowski, Wallace, Ellsworth, MacAleese, \& Cleveland, 2008). The benefit of doing so reduces the duration of the conflict episode, which also prevents any negative effects that may have occurred if the conflict continued. Considering this, de-escalation apologies are particularly important following defense responses or extinction of mild intensity AORs.

Apologies as methods of de-escalation are also related to the inter-response time between the aversive behavior and the apology. Research has suggested that engaging in an apology sooner rather than later following an aversive behavior has greater effects on producing a forgiving response from the victim (Ebesu Hubbard, Hendrickson, Fehrenbach, \& Sur, 2013; Jones, Moore, Schratter, \& Negel, 2001; Lazare, 2006). This would appear to be due to the effects of delay to reinforcement wherein apologies that occur with shorter inter-response times following an apology may have a shorter delay to reinforcement for the victim, therefore, reducing the likelihood of escalation (see related discussions in Hantula, 1992; Lattal, 2010).

There are also apologies that occur in the absence of offended responses, such as when a person apologizes for coughing loudly during a lecture. In these cases, apologies occur outside of the context of conflict and their occurrence may prevent any form of conflict from arising. However, their occurrence may be due to the similarities between the stimulus conditions of the present circumstance and those that have historically preceded conflict or offended responses. These types of apologies are also negatively reinforced and operate within unsignaled avoidance contingencies (Sidman, 1953, 1962), which may also describe how some individuals are overly 


\section{TONEY \& HAYES}

apologetic, wherein a person apologizes although the behaviors preceding the apology were not aversive for the other individual.

Alternatively, WORs produce a sort of deprivation of interacting with the victim, which might operate as an establishing operation (EO) (see Michael, 2000, 2004) that increases the likelihood of any response that regains access to interacting again. The probability of any apologetic response that has historically restored interaction with the victim is likely to increase as time without positive interactions with the victim elapses (for a related applied example, see Vollmer \& Iwata, 1991). Therefore, the victim's behavior arranges a positive reinforcement contingency for the offender's behavior that may produce interaction following a WOR.

\section{Formal Features of Apologetic Responses}

The form of the apologetic response refers to descriptions of the actual behaviors in which the offender engages rather than its function or effects on the victim's behavior. There are many formal features of apologies that are traditionally discussed such as requesting forgiveness (Szablowinski, 2012), discussing emotions (Hareli \& Eisikovits, 2006), expressions of empathy (Fehr \& Gelfand, 2009), accepting responsibility (Kador, 2009) and more. The following formal features all serve similar functions and may occur simultaneously or independently; however, they were selected for discussion based on their distinctiveness. These formal features are (1) the cessation of aversive behavior, (2) tacts of past and future behavior, (3) reparations and compensations, (4) compliance, (5) pre-conflict behavior, and (6) emotional responses.

Cessation of aversive behavior. Some offended responses immediately terminate an aversive behavior during its occurrence. In these moments, given that an increase in offended responses under similar situations occurs, the termination of the aversive behavior negatively reinforces the offended response. An example is when a child yells at a sibling, "Stop looking at me!" and the sibling quickly says, "Sorry!" and looks away. It is likely that the cessation of the sibling looking at the child negatively reinforces the child's yelling. If cessation of the aversive behavior did not occur under these circumstances, the offended response will likely undergo characteristic effects of extinction, such as increasing in intensity.

Tacts of past and future behavior. It is common for apologies to contain tacts of past behavior and/or future behavior. An apology with a tact of past behavior may take a form such as, "I'm sorry. I should not have done that." Traditional accounts maintain that these types of apologies might result in forgiveness due to their indication that the offender acknowledges their wrongdoing (Kador, 2009). Apologies that are tacts of future behavior might take the form of, "I promise not to do that again." These responses likely produce a forgiving response from the victim due to a history of being followed by more appropriate behavior under conditions similar to the initial aversive behavior. Additionally, being that these types of tacts have a relation to future behavior in the sense that they specify some aspect of that behavior, they may operate as forms of rules for the offender's behavior (see Skinner, 1969).

Reparations and compensations. Another potential feature of apologies is nonverbal behavior that serves as reparations (Lazare, 2004). Some types of reparative responses are directly related to the physical effects produced by the aversive behavior. If an aversive behavior produced a physical effect, such as a stained shirt or a broken dish, then the apologetic response might take the form of replacing these items or repairing the damage. There are also reparative response forms that have no relation to the physical effects of the aversive behavior but are reinforcing nonetheless. Here, the offender engages in behaviors that serve to somehow compensate the victim for the 
damages caused by his or her aversive behavior (for a related discussion, see Fehr \& Gelfand, 2009). For example, an individual might engage in an aversive behavior towards a neighbor and bring the neighbor cookies as an apology. Of course, the aversive behavior posed by the offender did not produce a deficit of cookies, yet the offer may allow for the relationship to be restored.

Reparative and compensatory apologetic response forms occur similarly as responses undergoing punishment in the form of overcorrection (e.g., Ollendick \& Matson, 1978). The procedure of overcorrection involves requiring an individual to restore the environment beyond its condition prior to a behavior that caused damage. Following the completion of the restoration, the punishment contingency is removed. Additionally, similar contingencies are utilized in legal matters, such as when an offender is required to pay punitive damages as a means of increasing the magnitude of punishment for the offense and to compensate the victim beyond his or her status prior to the offense (see Bush, 2014).

Compliance. Many offended responses include explicit verbal responses that operate as mands for specific behavior on the part of the offender. In these circumstances, an almost necessary feature of the apologetic response is compliance. Compliance may be a particularly important feature of the apology in the presence of offended responses that occur as a result of behavioral deficits or instances in which the offender fails to respond. As mentioned above, offended responses that occur under these conditions operate to coerce the offender to engage in some sort of behavior. Contingently complying or engaging in specified behavior in these circumstances likely has a positive reinforcing effect on the offended response that occasioned the behavior.

Although compliance may be necessary, it is not always independently sufficient, meaning that other features of the apologetic response may be required to produce a forgiving response. Imagine a situation in which a person finds out that a close friend is having a party and did not invite him or her. The person calls the friend and yells, "How could you have a party and not invite me?" The friend attempts to resolve the issue and responds with a calm, "You can come." Even though the friend complied with the person's mand, it is possible that the person will continue to engage in offended responses towards the friend with statements such as, "Well, now I don't want to come!" This type of response pattern indicates that in this case, compliance is not the sole reinforcer, being that the increase in response intensity and aggressiveness resembles effects of extinction (see Azrin et al., 1966).

Pre-conflict behavior. In some circumstances, the offender may simply behave as he or she did prior to the conflict to produce a forgiving response. In doing so, well-established contingencies (i.e., those that were operating before the conflict) are reinstated (for an experimental example, see Baker, Steinwald, \& Bouton, 1991), and the effects of the conflict seem to diminish. This likely occurs due to the response-independent presentation of a reinforcer (i.e., offender's pre-conflict behavior), which then occasions related behavior on the part of the victim that was extinguished during the conflict. As a result, interactions may ensue as they did prior to the conflict, such as when a conflict occurs between partners and the victim escapes the situation. Upon their next interaction, the offender asks, "So, how was your day?" and the victim responds as he or she normally would prior to the conflict. In these circumstances, pre-conflict behavior may have the same effect on the victim's behavior as an apology but without the occurrence of a more explicit apologetic response form.

Emotional responses. The final feature of apologetic responses is broad, however, it is likely the most important to discuss. There are features of apologetic responses that are traditionally discussed as expressions of sincerity, genuineness, remorse, regret, and guilt. These include overt responses of the offender that take nonverbal forms such as looks of startle, changes in body 


\section{TONEY \& HAYES}

posture or stance, facial expressions, signs of fear, crying, and also verbal forms such as pleading for forgiveness, tacts of present pain or emotional states, etc. It is generally considered that these features of apologies, particularly those referred to as sincerity, are the most likely to produce a forgiving response from the victim (e.g., Bachman \& Guerrero, 2006; Darby \& Schlenker, 1982; Ebesu Hubbard et al., 2013; Schumann, 2012; Sidelinger, Frisby, \& McMullen, 2009; Zechmeister, Garcia, Romero, \& Vas, 2004). These features of apologetic responses will be referred to as emotional responses. ${ }^{9}$

In some cases, it appears that following the onset of conflict, contingencies alter so that the products of the offender's emotional responses become the sole reinforcer for the victim's offended responses that occur rather than the resolution of the problem. Skinner $(1953,1969,1974$, $1985,1986)$ conceptualized such contingencies whereby observing signs of damage to an opponent may function as a reinforcer (for experimental examples, see Azrin, Hutchinson, \& Mclaughlin, 1965; Azrin et al., 1964). Despite the occurrence of an apology or compliance with a command, the victim may withhold forgiveness until adequate signs of sufferance on the part of the offender are observed (Lazare, 2004). Only then, and contingent upon these responses, might a victim forgive. Without such response features, the victim might state, "I don't believe that you mean it" or perhaps feel the offender has not learned their lesson. A parent may continue to yell at a child until the child displays a look of fear, the spouse may elaborate on his or her pain until the other admits fault, the friend might continue to ignore phone calls until the other pleads for forgiveness.

The victim's contingencies surrounding the offender's emotional responses are similar to those that are commonly present in revenge. In instances of revenge, a person causes another pain, and the victim responds in such a way to produce indicators of comparable pain. Accordingly, once a victim experiences an aversive behavior, an EO likely will be produced in which observing the products of the offender's overt emotional responses may function as a reinforcer. For the victim, the offender's apologetic responses, particularly emotional responses, appear to be within the same stimulus class as signs of damage to an opponent that occur during instances of revenge. This becomes more apparent when considering the root of the term "sorry" to be a translation of terms such as "sore" and "painful." In traditional terms, to hear that the offender feels bad for what he or she did somehow makes the victim feel better and only after such is resolution possible.

In stark contrast with traditional views, from a behavior-analytic perspective, all formal features of the apology discussed above, are responses that have been learned through a history of these behaviors producing reinforcement from the victim, most usually in the form of forgiveness. This means that they are not considered expressions of the offender's guilt, shame, remorse, sincerity, etc.; they are simply forms of the offender's behavior that operate to modify the victim's behavior in a preferred manner under the current circumstances.

\section{The Source of Control of Apologies}

Perhaps one of the most important understandings provided by a behavioral analysis that contrasts with traditional views is that of the source of control for apologetic responses. It is said that people apologize for what they did and it is believed that one apologizes as a result of his or her aversive behavior. However, at the point of apologizing, the aversive behavior is in the past and therefore cannot exclusively exert control over present behavior (see related discussion in

\footnotetext{
${ }^{9}$ It is important to note that the response features described here are not considered emotions themselves, but instead overt behaviors whose products are commonly described as the expression of emotions.
} 
Hayes, 1992, 1998). Instead, it is the victim's offended response that exerts control over the apologetic response. Given the history of the aversive behavior, the offended response and other stimuli present at the time of conflict now exert control over particular forms of the offender's verbal behavior that are related to past events. Therefore, the relation that exists between the apology and the aversive behavior is that the apology is the response to the victim's consequence to the aversive behavior. This is apparent if we consider the differences in conditions under which the aversive behavior and the apology occur. The aversive behavior occurred under one set of conditions, and the apology occurred under conditions presented by the offended response, which serves as a consequence to the aversive behavior.

This is also true with the relation between the apology and the reduction in probability of future aversive behaviors. It might be assumed that the apology somehow illustrates a reduced probability of the aversive behavior occurring again (for a related discussion, see Davis \& Gold, 2011; Wooten, 2009). Perhaps apologies of particular forms were followed by a preferred change in behavior, as discussed above. While this may be true, these responses are not controlled by the reduced probability of future aversive behaviors (see related discussion in Hayes, 1992, 1998). Assuming such would be a teleological error: placing the source of control for the present in events that are yet to occur. Yet, this is so widely believed that remorse and other emotional descriptions of apologetic responses are commonly discussed variables in legal matters and their effects on mitigation or the reduction of a criminal's sentence (see Bagaric \& Amarasekara, 2001; Bibas \& Bierschbach, 2004; Tudor, 2008; Ward, 2006; Zhong et al., 2014). To our knowledge, there is no empirical evidence to support the assumption that the occurrence of apologies, particularly those that are composed of emotional responses, generally indicates a reduction in the future probability of aversive behaviors.

This highlights the issue of what particular events reinforce the offended response. It is not the potential future reduction in aversive behaviors, nor is it the undoing of a previous aversive behavior; it is the immediate features presented in the offender's apologetic response that reinforces an offended response. One potential reason that apologies come to have such conditioned reinforcing effects is that their occurrence has been associated with changed behavior under particular conditions; behavior that does not have aversive functions for the victim's behavior. In the presence of such apologetic responses, a threat presented by the aversive behavior may be reduced allowing the behavior of the victim to return to manners similar to those prior to the aversive behavior, or in other words, to forgive.

\section{Sufficient and Insufficient Apologies}

These formal features of the apology are subject to selection through the reinforcement provided by the victim's forgiving response. The process of selection in these instances occurs through differential reinforcement in which the victim reinforces, by way of forgiving, only particular apologetic response while extinguishing all other forms. Apologetic responses that fail to produce a forgiving response are extinguished and referred to as insufficient apologies. ${ }^{10}$ Following extinction of these response forms, other members of the same response class may occur. The offender may plea, cry, become aggressive, attempt to justify his or her actions, make

\footnotetext{
${ }^{10}$ In traditional literature, the term effective is commonly used to describe apologies that achieve forgiveness. Insufficient and sufficient are used here to emphasize the response requirement of the contingency arranged by the victim during conflict.
} 


\section{TONEY \& HAYES}

statements such as, "But I said I was sorry!" among other responses historically followed by a forgiving response. This increase in frequency, magnitude, and variability should be expected and are known side effects of extinction (for clinical examples, see Grow, Kelley, Roane, \& Shillingsburg, 2008; Kelly \& Hake, 1970; Kinloch, Foster, \& McEwan, 2009; Morgan \& Lee, 1996).

The apologetic response form that meets the response requirements for the present contingencies arranged by the victim will be referred to as a sufficient apology. These apologetic response forms exert stimulus control over the victim's forgiving response. In the event that the victim accepts the offender's apology, he or she then engages in a response that serves to reestablish contingencies that were operating prior to the conflict, referred to as the forgiving response.

\section{The Victim's Forgiving Response}

The victim's forgiving response is defined as any response that initiates the victim behaving with respect to the offender as he or she did prior to the offender's aversive behavior. ${ }^{11}$ As with apologies, the forgiving response is defined functionally rather than in terms of the form of the victim's behavior. Following a conflict, the victim might engage in nonverbal behaviors such as hugging the offender or smiling, or verbal behaviors such as stating, "I forgive you," or thanking the victim for apologizing. The victim could also simply begin interacting with the offender as he or she did prior to the conflict and this would constitute a forgiving response. It is the reinstatement of well-established contingencies, distinct from those operating during conflict, surrounding the behavior of both interacting individuals that signifies forgiveness.

\section{The Forgiving Response as a Consequence}

Depending on the victim's behavior during the conflict, the forgiving response may positively or negatively reinforce the offender's apologetic response. The contingent reintroduction of the victim's reinforcing behaviors likely positively reinforces the offender's apology, and it may also mark the cessation of any aversive forms of responding from the victim, which negatively reinforces the offender's apology. ${ }^{12}$ In either case, the likelihood of the offender engaging in similar apologetic response forms during subsequent conflicts may be increased following the victim's forgiving response.

Since the forgiving response reinforces the apology, it is a critical variable in the resolution of conflicts, and there are particular effects that it may produce given these capabilities. First, as previously mentioned, the form of the apology is to a large extent selected by the forgiving response. This also means that the victim is in a position to withhold forgiving until the offender engages in a preferred apologetic form. For example, if a spouse preferred the partner take him or her out more often, the spouse can withhold forgiveness during conflict until the partner offers to do so. During subsequent instances of conflict, the spouse will likely engage in a similar apologetic response form. However, if the victim were to withhold forgiveness until an apologetic response form that required a great deal of effort for the offender occurred, the apologetic response may

\footnotetext{
${ }^{11}$ See Skinner's (1957, p. 168) definition of forgiveness as the "reduction of a conditioned aversive stimulus or threat after a response has been made."

${ }^{12}$ See Skinner's (1953, p. 317) discussion of forgiveness as a form of negative reinforcement.
} 


\section{APOLOGIES, FORGIVENESS, AND INTERPERSONAL CONFLICT}

cease to occur or reduce similarly as if it were punished due to the effects of increased response effort (see related discussion in Friman \& Poling, 1995).

While this feature of the forgiving response can produce more sufficient apologies as they pertain to the present relationship, under other circumstances, it might select maladaptive forms of the offender's behavior. For instance, if a victim were to forgive an apologetic response form consisting of crying, screaming, pleading, and the like, it is more likely that the offender will engage in and experience similar forms of behavior on subsequent occasions. On the other hand, if the victim forgives the offender following a simple, "I'm sorry," the offender will likely engage in this form during subsequent conflicts, even those in which a response form of greater magnitude would be more appropriate.

Additionally, if the forgiving response occurs before features of the offended response effectively punish the aversive behavior, there is a possibility that the latency between the forgiving response and apology might reduce or void the punishing effects of the offended response. This might be described traditionally as "letting the offender believe that what they did was okay." If this occurs, the likelihood of the offender engaging in further aversive behaviors is unaltered by the offended response (for a related discussion, see McNulty, 2011). This relates to the effects of the duration of the offended response discussed above. Consider that a child says a derogatory statement to the mother and she responds in an offended manner such as, "We do not speak like that!" In return, the child apologizes, and the mother quickly forgives the child. She may even praise the child for apologizing by saying, "That was very nice of you to apologize." The mother's offended response likely had little effect on the child's behavior because the forgiving response occurred before to the offended response had any punishing effects. Also, the child likely learned that a simple apology was an effective means of avoiding further punishment.

The issue of how the forgiving response might alter the punishing effects of the offended response can be of great concern in more significant situations, such as those related to abuse and violence. As discussed above, the offender's apologetic response serves a discriminative function for the victim's forgiving response and this may occur even in situations in which forgiving and continued interaction following resolution may ultimately result in further opportunities for harm to occur towards the victim. The forgiving response might completely void any punishing effects the offended response might have had on aversive behaviors and features of the conflict may not have altered the stimulus control exerted over aversive behaviors. Therefore, the occurrence of aversive behavior persists and as a result, the victim may be in a compromised situation (for a thorough discussion on these issues, see Bell \& Naugle, 2005; McNulty, 2011; Myers, 1995).

\section{Motivating Operations Related to Forgiveness}

In the event that the victim engages in a WOR, the victim may experience a form of deprivation of interaction with the offender that might operate as an EO for the forgiving response. This deprivation increases as time passes and forgiving the offender provides the victim the ability to interact with the offender once again, which likely functions as positive reinforcement for the forgiving response. Since increasing durations of deprivation increases response rates (e.g., Logue \& Pena-Correal, 1985), under these conditions, it may be the case that the greater the duration of time without interacting, the greater the probability that the victim will forgive regardless of an apology.

The victim's interactions with others besides the offender may also affect the likelihood of the victim engaging in a forgiving response. Consider that the offender is the victim's primary source 


\section{TONEY \& HAYES}

for various types of social reinforcement. If this is the case, the victim may come to forgive the offender more readily as his or her deprivation of social reinforcers is unaltered through the interactions with others. Alternatively, while refraining from interacting with the offender, the conflict might operate as an EO for the victim to begin seeking other social reinforcers (i.e., friends, family, other partners, etc.). The interaction with others may reduce the deprivation of these reinforcers, operating as an abolishing operation (AO) and potentially delay forgiving the offender (see summary in Table 1).

\section{Resolution}

The contingencies that are reintroduced following the forgiving response play critical roles in the behavior of both the victim and the offender as well as the resolution of subsequent conflicts. If the offender's behavior under similar conditions as the initial aversive behavior is modified in an appropriate way following the conflict, similar occurrences of conflict related to those conditions will likely cease to occur. In doing so, in traditional terms, the victim restores trust in the offender.

Table 1: Summary of responses involved in interpersonal conflict with their potential effects and related variables.

\begin{tabular}{|c|c|c|c|c|c|}
\hline $\mathbf{S}^{\mathbf{D}}$ & Response & $\begin{array}{c}\text { Consequential } \\
\text { Effects }\end{array}$ & $\begin{array}{l}\text { Factors that Enhance } \\
\text { Consequential Effects }\end{array}$ & $\begin{array}{c}\text { Factors that Increase } \\
\text { Likelihood of Response } \\
\text { (EOs) }\end{array}$ & $\begin{array}{c}\text { Factors that Decrease } \\
\text { Likelihood of Response } \\
\text { (AOs) }\end{array}$ \\
\hline $\begin{array}{l}\text { Aversive } \\
\text { Behavior } \\
\text { (Offender) }\end{array}$ & $\begin{array}{l}\text { Offended } \\
\text { Response } \\
\text { (Victim) }\end{array}$ & $\begin{array}{l}\text { Punishes } \\
\text { Aversive } \\
\text { Behavior }\end{array}$ & $\begin{array}{l}\text { High intensity AOR } \\
\text { Extended WOR } \\
\text { Delay between } \\
\text { offended response and } \\
\text { forgiving response } \\
\text { Continuous schedule } \\
\text { of engaging in } \\
\text { offended responses }\end{array}$ & $\begin{array}{l}R=\text { Offended Response } \\
\text { Extinction of conflict } \\
\text { assertive responses } \\
\text { and/or mild AORs } \\
\text { High frequency of } \\
\text { aversive behaviors } \\
\text { Behavioral } \\
\text { deficits/failure to } \\
\text { respond }\end{array}$ & $\begin{array}{l}R=\text { Offended Response } \\
\text { Reinforcement of } \\
\text { conflict assertive } \\
\text { responses } \\
\text { Extinction of previous } \\
\text { offended responses }\end{array}$ \\
\hline $\begin{array}{l}\text { Offended } \\
\text { Response } \\
\text { (Victim) }\end{array}$ & $\begin{array}{l}\text { Apologetic } \\
\text { Response } \\
\text { (Offender) }\end{array}$ & $\begin{array}{l}\text { Reinforces } \\
\text { Offended } \\
\text { Response }\end{array}$ & $\begin{array}{l}\text { Ammediacy of } \\
\text { apologetic response } \\
\text { Cessation of aversive } \\
\text { behavior } \\
\text { High magnitude } \\
\text { apologetic response } \\
\text { (i.e., emotional } \\
\text { responses, reparations) }\end{array}$ & $\begin{array}{l}R=\text { Apologetic Response } \\
\text { Extended WOR } \\
\text { High intensity AOR } \\
\text { (without producing } \\
\text { escape or defense } \\
\text { responses) }\end{array}$ & $\begin{array}{l}R=\text { Apologetic Response } \\
\text { Low intensity AOR } \\
\text { Extinction of previous } \\
\text { apologetic responses }\end{array}$ \\
\hline $\begin{array}{l}\text { Apologetic } \\
\text { Response } \\
\text { (Offender) }\end{array}$ & $\begin{array}{l}\text { Forgiving } \\
\text { Response } \\
\text { (Victim) }\end{array}$ & $\begin{array}{l}\text { Reinforces } \\
\text { Apologetic } \\
\text { Response }\end{array}$ & $\begin{array}{l}\text { Ammediacy of } \\
\text { Forgiving Response } \\
\text { Termination of } \\
\text { Offended Response } \\
\text { Low response effort } \\
\text { for sufficient } \\
\text { apologetic forms }\end{array}$ & $\begin{array}{l}R=\text { Forgiving Response } \\
\text { Deprivation of } \\
\text { interaction with } \\
\text { offender } \\
\text { High magnitude } \\
\text { apologetic response }\end{array}$ & $\begin{array}{l}R=\text { Forgiving Response } \\
\text { Alternative sources for } \\
\text { similar reinforcers } \\
\text { Minimal deprivation of } \\
\text { interaction with offender } \\
\text { Insufficient apologetic } \\
\text { response forms }\end{array}$ \\
\hline
\end{tabular}


If the offender continues to engage in aversive behaviors under conditions related to the initial event, the likelihood of the victim escaping the relationship might increase, and the status of the relationship may be threatened. Repeated occurrences of aversive behaviors following resolution may reduce motivational variables for the victim to respond, which might mimic the effects of learned helplessness (see Maier \& Seligman, 1976). Furthermore, the continued engagement of aversive behaviors from the offender may produce effects similar to the extinction of the offended response. Therefore, it is also likely that during future episodes of conflict related to behavior similar to the initial aversive behavior, the victim might engage in higher intensity AORs, longer durations of WORs, and sufficient forms of the apology may require greater response effort on the part of the offender (reparations, emotional responses, etc.). In traditional terms, continued engagement of aversive behaviors following resolution may result in the victim feeling helpless and that the problems faced in the relationship are irresolvable.

Alternatively, if the victim forgives the offender yet his or her behavior remains aversive for the offender, the apologetic response may be extinguished or punished. Referred to elsewhere as pseudo-forgiveness (Hebl \& Enright, 1993), the victim may emit the words "You are forgiven," however, if he or she continues to respond punitively towards the offender, then the contingencies have not been reestablished, and forgiveness has not occurred. This can be seen in situations in which the victim forgives the offender yet he or she still holds a grudge.

It is important to note that despite resolution, the behaviors that initiated the conflict become part of both individuals' histories. As a result, there are likely to be residual effects of the conflict, as individuals cannot depart from their histories (see Hayes, 1992). Stimuli related to the conflict may continue to occasion behavior from both individuals, and this may appear in a number of fashions. In some instances following conflict, while the victim has forgiven the offender, he or she may behave differently towards the offender with respect to related behaviors. For example, if an offender engaged in an act of infidelity, contingencies may be established regarding how the offender uses his or her phone, the times at which he or she arrive home, providing details regarding his or her conduct at events in which the victim is not present, and so on.

The behaviors that occurred during the conflict also become part of both individuals' histories. Meaning, during ongoing conflict, the responses of the individuals involved are typically operating under aversive contingencies. These contingencies produce various forms of aggressive behavior, such as defense responses on both sides, as outlined above. This often results in additional issues that may need to be resolved in addition to those related to the initial aversive behavior. While the offender apologizes for the aversive behavior, the victim might also apologize for his or her offended response to aversive behavior, particularly AORs.

This issue brings into question the meaning behind the traditional saying, "forgive and forget" (see Noreen, Bierman, \& Macleod, 2014). In contrast with traditional views, forgetting from a behavioral perspective refers to the diminishing stimulus control as a result of time passing without the presentation of discriminative stimuli (Keller \& Schoenfeld, 1950; Skinner, 1957). While the victim may interact with the offender similarly to ways prior to the conflict, stimuli related to the conflict, or even those that have some generalized similarity, may continue to exert control over some of the victim's behavior. This also describes instances of conflict in which an individual will bring up previous conflicts as a result of the stimulus control exerted by the present circumstances. 


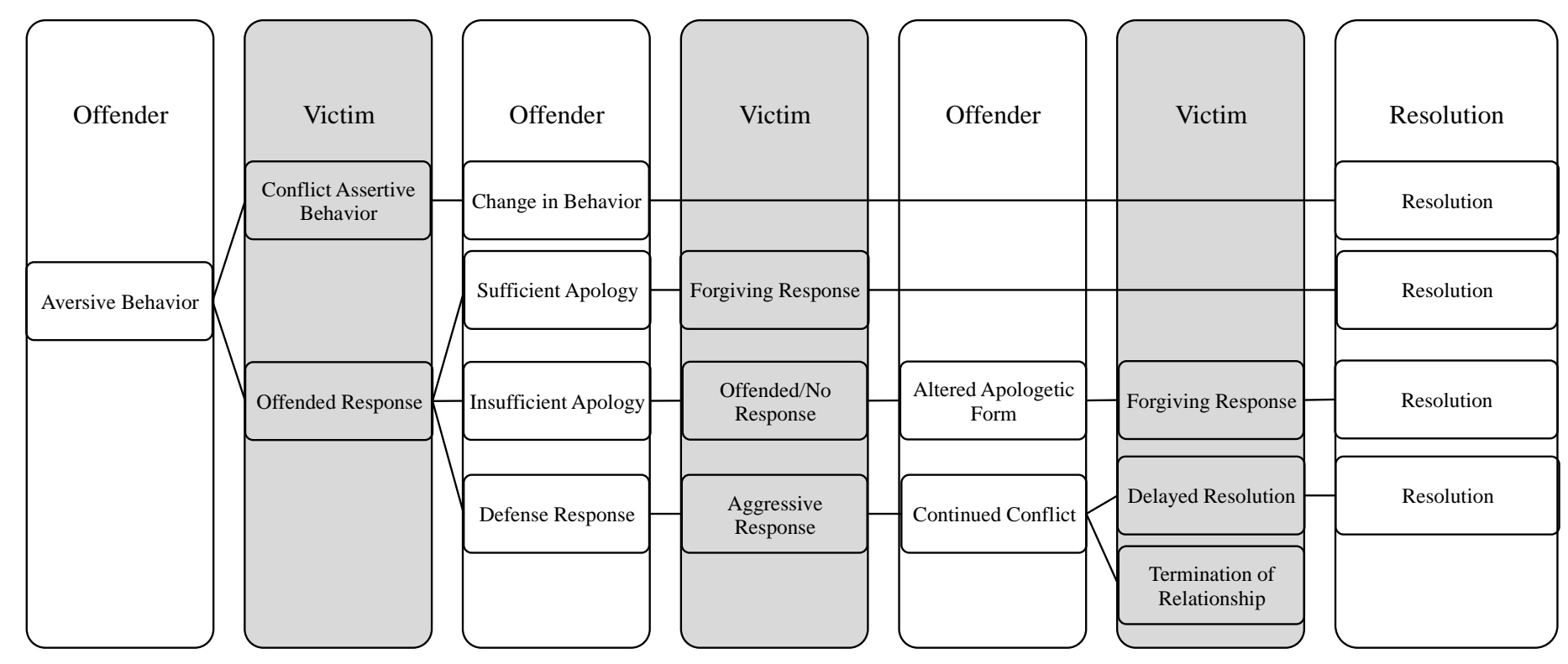

Figure 1. Potential outcomes given the occurrence of particular response forms during conflict.

\section{Applications}

Episodes of interpersonal conflict are composed of multiple behaviors of both individuals. Based on the present analysis, depending on the occurrence of particular behaviors and their relations to other behaviors, the conflict unfolds in a variety of ways (see Figure 1). Some of these forms of interaction are beneficial while others likely contribute to the frequency of conflict within the relationship. Various types of behaviors that have aversive functions from both individuals occur that are likely reinforced, and as a result, the occurrence of conflicts persists creating a harmful pattern within the relationship. In order to reduce episodes of conflict, goals should be (1) the reduction of aversive behaviors, (2) the reduction of aggressive offended responses (AORs), (3) the maintenance of effective assertive behaviors that modify the opposing individual's behavior without the use of aversive means, and (4) the reinforcement of appropriate alternatives to aversive behaviors. There are many widely used and well-supported behavior-analytic methods and procedures that could aid in achieving these goals; selected as examples to illustrate are deprivation, differential reinforcement, and stimulus control.

\section{Deprivation (Time Without Interaction)}

Deprivation in this sense is different than how it is utilized in most basic behavioral research (i.e., time elapsed since last feeding) but studies have shown that deprivation in the form of time without social interaction can have similar effects (see related discussions in Gewirtz \& Baer, 1958; McGill, 1999; Michael, 2000). There are a number of ways that time without interacting could improve how individuals overcome conflicts.

First, by way of negative punishment, taking time apart can produce a reduction in aversive behaviors, such as when the victim engages in a WOR. There are also advantages of engaging in WORs when compared to AORs. Since both forms of offended responses might result in a 
reduction in the frequency of the aversive behavior, it has been shown that forms of positive and negative punishment can have similar reductive effects (e.g., McMillan, 1967). However, methods of negative punishment do not carry with them the many unwanted collateral effects of positive punishment such as escape from the punisher, aggression, and counter-control (Johnston, 1972; Sidman, 1989; Skinner, 1971, 1974).

Taking time apart might also increase the reinforcing effectiveness of various types of interactions. In the event the victim engages in a WOR, the EO that is produced for the offender's behavior includes a value-altering effect (Michael, 2004) and increases the value of interacting with the victim. This is likely followed by what is traditionally referred to as a rekindling after a conflict and might have a positive effect on the quality of interactions. Concurrently, the victim experiences deprivation of interacting with the offender that not only increases the likelihood he or she will forgive, but also reduces the response requirements for sufficient apologies (for a related applied example, see Gottschalk, Libby, \& Graff, 2000). Therefore, apologetic response forms that were extinguished during conflict might be reinforced following time apart.

Additionally, when individuals take time apart, their behavior is no longer under the control of the contingencies that operated during the conflict. The aggressive behavior that occurs in conflicts is under the control of those specific contingencies and apart from the conflict, the individuals' behaviors come under the control of different contingencies, which are less likely to be aversive. This is observed when people proclaim, "I said a lot of things I didn't mean." When distanced from the conflict, individuals respond differently and potentially in a more constructive manner. This allows for the responses to be under control of the behavior of the other individual at the time of resolution with less intrusion of the aversive effects of the conflict. This reflects a sort of recovery from punishment (e.g., Boroczi et al., 1964; Filby \& Appel, 1966) that occurs wherein responses that were punished during conflict may recover as a result of time without the presence of stimuli correlated with punishment.

\section{Differential Reinforcement}

Differential reinforcement offers an effective alternative to punishment (Johnston, 1972; Lavigna \& Donnellan, 1986) that involves two features: (1) extinction of particular response forms and (2) the reinforcement of functionally similar response forms. The extinction component of differential reinforcement will likely be an effective means to reduce AORs. These responses are the root of most conflicts and they are often maintained through immediate apologetic responses. If the offender simply refrains from responding to an AOR in a manner that might reinforce it (i.e., refraining from apologizing immediately), this might produce a reduction in the frequency of these types of responses. However, considering the effects of extinction, this runs the risk of the AOR increasing in intensity or changing forms such as threats, insults, turning the tables, etc. (for a related discussion, see Thomas \& Millar, 2008). This can be seen when a victim engages in an AOR but it does not get a rise from the offender and then engages in a different response form that serves the same function. Imagine a teenager stating to a parent, "You always take my brother's side!" The parent calmly responds with, "We will talk about this later," and the teenager's response modifies in form through saying, "You just don't care about how I feel!" Not only might this type of extinction aid in the reduction of AORs, but it also shortens the duration of the conflict and prevents the occurrence of verbal responses from the offender that may worsen the situation.

Another possible method to extinguish AORs is for the offender to continue engaging in aversive behaviors despite the occurrence of AORs. Consider a situation in which an individual is 


\section{TONEY \& HAYES}

routinely late to meet a friend when they have plans. The friend may engage in AORs the first many times the individual is late but after such responses fail to improve the individual's timeliness, he or she will likely stop. However, this might not be an ideal method under certain circumstances or within particular relationships. Through continued engagement of aversive behaviors and failed attempts to modify such behaviors, as discussed above, there is a possibility that the victim will likely begin avoiding the offender, characteristic of the effects of aversive stimuli.

The reinforcement component of differential reinforcement could improve the selection of more appropriate response forms during conflicts. Being that offended responses function to modify the offender's behavior in a given way, there are alternative means of achieving such an outcome without the use of aversive techniques; therefore avoiding the accompanying side effects and experiencing prolonged conflict. The victim could engage in responses that exert stimulus control over the offender's alternative response forms to conditions under which the aversive behavior occurred, referred to as conflict assertive behavior (see Rakos, 1991).

Heimberg, Montgomery, Madsen, and Heimberg (1977) described assertive behavior as "effective social problem solving," and further defined it as, "behavior that is performed in order to maximize the reinforcement value (the algebraic sum of positive and negative factors) of a social interaction for all persons involved." (p. 954). Assertive behavior, particularly as it relates to conflict, offers an alternative to aggressive behaviors typically observed in conflict and includes specific behaviors the victim may engage in to produce a desirable change in the offender's behavior. Even more, assertive behavior has been found to reduce the likelihood of aggressive responses and improve compliance (Hollandsworth \& Cooley, 1978).

While there are no specific forms of behavior that are certain to be effective given the particular details of every episode of conflict, the research related to assertive behavior has produced a thorough foundation of behavioral components that are generally effective in behavior change during conflict. The majority of the literature on assertive behaviors explores the verbal content of assertive behavior (Serber, 1972). Some of these verbal behaviors, for example, include compliance content (Eisler, Miller, \& Hersen, 1973), behavior change requests that describe the aversive behavior and requests for alternative behavior on the part of the offender, statements that are direct, specific, and respectful, compliments or praise, attempts to compromise (Rakos, 1991), and the use of "I" statements versus "you" statements (Hollandsworth \& Cooley, 1978).

Also included in effective conflict assertive behavior are paralinguistic components, which are dimensions of the vocal response outside of the content of verbal statements (Rakos, 1991; Serber, 1972). Research has found that although particular dimensions depend on the present circumstances, conflict assertive behaviors should be of intermediate voice volume and intonation, moderately loud, with moderate response latency and duration. Nonverbal behaviors such as eye contact, body language, and facial expressions and interactive skills such as selecting the most effective timing and context to engage in conflict assertive behaviors have also been explored. We refer the readers to Rakos (1991) for more thorough information on conflict assertive behavior.

Through engaging in effective conflict assertive behaviors, the victim responds to the aversive behavior in a manner that produces desirable behavior change on the part of the offender without aversive means. Under similar subsequent circumstances, if the offender engages in an appropriate alternative to the initial aversive behavior, this will likely reinforce and improve the stimulus control over the victim's assertive behavior. Over time, effective conflict assertive responses and more desired behavior will be reinforced from both individuals, resulting in a more positive nature of the relationship. This would be considered an instance of the offender utilizing differential 


\section{APOLOGIES, FORGIVENESS, AND INTERPERSONAL CONFLICT}

reinforcement of alternative behaviors (DRA) in which assertive responses are reinforced while offended responses are extinguished (for related applied examples, see Marcus \& Vollmer, 1996; Piazza, Moes, \& Fisher, 1996; Roane, Fisher, Sgro, Falcomata, \& Pabico, 2004).

Furthermore, reinforcement from the victim will be required to increase the frequency of these alternative response forms of the offender's behavior under these conditions. If an offender engaged in an aversive behavior under particular conditions at one point, he or she is likely to engage in such behaviors under similar conditions again. However, following a conflict assertive response to the initial occurrence, if the victim reinforced the offender's alternative behavior when in a similar condition to the one present during the initial aversive behavior, the offender's behavior under these conditions will likely change. This will potentially modify the stimulus control exerted by these conditions to that which produces more favorable behaviors, reducing the overall probability of aversive behaviors and potential conflicts. Such an occurrence would be an example of DRA for the offender's aversive behavior.

Lastly, the reinforcement of desirable behaviors that are unrelated to conflicts should be addressed. All too often in relationships, over time, individuals tend to punish the aversive behaviors of the other rather than reinforcing more positive behaviors. This can result in general unhappiness from both individuals and it increases the likelihood of termination (see Sidman, 1989). However, rather than punishing the aversive behaviors of the other, if individuals reinforce behaviors of the other that are reinforcing for him or her, it will likely have an overwhelmingly positive effect. Even though this is a relatively simple behavioral method, its effects are possibly quite profound. This approach is similar to the procedure of differential reinforcement of other behavior (DRO) in which reinforcement is provided contingent on behaviors distinct from and absent of those targeted for reduction (for an applied example, see Cowdery, Iwata, \& Pace, 1990). The result is potentially the increased frequency of the offender's desirable behavior with a simultaneous reduction in the frequency of aversive behaviors.

\section{Conclusion}

We have attempted to provide a thorough behavioral analysis of apologies, forgiveness, and interpersonal conflict, although with the understanding that there are many unique features of each particular episode of conflict that may not be accounted for. While there is no empirical evidence specifically related to these features of conflict within the behavior-analytic tradition, assumptions have been made based on findings in basic and applied research as well theoretical interpretations from within our field. We believe the functional relations explored in these works reflect those commonly observed in interpersonal conflict. However, a number of conclusions have been drawn regarding particular features of conflict that directly challenge traditional views. To conclude, we have created a brief summary to allow the reader to further consider these points.

1. Increasing the rate at which we become hurt and offended. It appears that apologetic behavior has a reinforcing effect on the victim's offended response forms. Once a victim's offended response is reinforced, it is likely that the behavior will be repeated; but even more concerning is that the stimulus properties that evoked this behavior may generalize across stimulus conditions and social contexts. This not only describes increases in the frequency in which an individual is offended, but it results in an increase in the range of stimulus or social conditions that bring about this behavior. In other words, one's history of reinforcement for offended responses ultimately shapes the products of behaviors one responds to as if they were aversive in social situations. 


\section{TONEY \& HAYES}

Kowalski (2001) emphasized the subjective nature of aversiveness stating that whether or not an act is viewed as aversive "depends on the perspective of the viewer" (p. 7). One's unique history of reinforcement of such responses contributes to one's perspective.

2. The establishment of "revenge" contingencies within relationships. The development of contingencies surrounding apologies and the observation of emotional responses is a critical concern in relationships. Once an offended response occurs and is reinforced by an apologetic response, it is possible that a form of rivalry may begin to develop within the relationship wherein the observation of the other person's failure, pain, embarrassment, shame, regret, fear, jealousy, and so on reinforces the behavior that produced such responses. This effect becomes reciprocated between the individuals as the offender, after experiencing the offended response, might now be in a position where he or she has experienced a threat and the observation of the victim's emotional responses is also reinforcing. The effects of these contingencies likely perpetuate within the relationship making conditions increasingly aversive for both individuals involved.

3. The relation between apologies and a change in behavior. Based on the discussion of the source of control of apologies, we cannot assume that any apologetic response exerts control over future behavior. Apologies certainly cannot undo a previous aversive behavior; the same understanding applies to apologies' predictive abilities. Being that in the moment of conflict, a reduction in an aversive behavior cannot be observed, it must be assumed that the immediate reinforcement for the victim's offended responses is the formal features of the offender's apologetic response. Therefore these responses are likely to be maintained, despite any reduction in future probability of the aversive behavior. While offended responses may produce momentary reinforcement in the form of apologetic responses, their repeated occurrence will ultimately lead to a hostile nature of interacting within the relationship or even its termination.

4. The use of aversive control methods to shape relationships. Although the behaviors of becoming upset, apologizing, and forgiving are regular parts of our repertoires, it appears that these practices have elements of coercion and aversive control (see Sidman, 1989; Skinner, 1971). Forms of coercion become a regular part of an individual's repertoire, as these methods are generally quite effective in achieving the control of the other's behavior. This is not to say that individuals should go without attempting to modify the other person's behavior in a given way, but instead modify how they attempt to achieve such a change.

5. The initiating behavior of conflict. It is commonly thought that it is the offender's aversive behavior that initiates a conflict. However, based on this analysis, this is not the case. Contrary to traditional assumptions, it appears that the behavior of concern in conflict is the victim's response to this behavior. While aversive behaviors have a negative impact on the victim, it is generally the victim's response to these behaviors that ultimately gives way to either a healthy resolution or a prolonged conflict. This does not mean that conflict is the victim's fault or that a victim should never be hurt or offended, but rather that the response that occurs in the presence of the aversive behavior plays a critical role in resolution and that responding constructively to these issues may prevent the occurrence of conflict altogether. 


\section{APOLOGIES, FORGIVENESS, AND INTERPERSONAL CONFLICT}

6. The necessity of apologizing and forgiving in conflict resolution. Since interpersonal conflict occurs as a means to modify others' behavior and more effective methods exist, it might be the case that the practices of apologizing and forgiving are not necessary to maintain a healthy relationship. These practices are additional, potentially aversive forms of interaction that occur in response to a behavioral issue within relationships. They often lead to immediate and momentary resolution, but the delayed effect is likely that of an increased probability of similar occurrences. A better solution, as it appears, would be to instead direct efforts towards discovering more constructive methods to modify each other's behavior. The work conducted on assertive behavior, with an emphasis on behavior change, provide guidelines for particular response forms that may be more effective in times of conflict.

Interpersonal conflicts are generally difficult experiences for both individuals, and often the approaches made to resolve the issue may be ineffective or perhaps make future conditions worse. This may be partly due to how we have come to view the traditional approaches of apologizing and forgiving. Through relying on emotion-based analyses and formal accounts of behavior, individuals are likely to take a wrongful course of action when attempting to resolve conflicts. However, through a behavioral approach, we come to a better understanding of the conditions under which these behaviors occur and their effects on the other person's behavior. As a result, we may better find resolution and potentially experience healthier interactions within relationships.

\section{References}

Abramowitz, A. J., \& O’Leary, S. G. (1990). Effectiveness of delayed punishment in an applied setting. Behavior Therapy, 21, 231-239. doi: 10.1016/S0005-7894(05)80279-5

Appel, J. B. (1963). Punishment and shock intensity. Science, 141, 528-529. doi: 10.1126/science.141.3580.528-a

Azrin, N. H. (1960). Effects of punishment intensity during variable-interval reinforcement. Journal of the Experimental Analysis of Behavior, 3, 123-142. doi: 10.1901/jeab.1960.3-123

Azrin, N. H., Hutchinson, R. R., \& Hake, D. F. (1966). Extinction-induced aggression. Journal of the Experimental Analysis of Behavior, 9, 191-204. doi: 10.1901/jeab.1966.9-191

Azrin, N. H., Hutchinson, R. R., \& McLaughlin, R. (1965). The opportunity for aggression as an operant reinforcer during aversive stimulation. Journal of the Experimental Analysis of Behavior, 8, 171-180. doi: 10.1901/jeab.1965.8-171

Azrin, N. H., Hutchinson, R. R., \& Sallery, R. D. (1964). Pain-aggression toward inanimate objects. Journal of the Experimental Analysis of Behavior, 7, 223-228. doi: 10.1901/jeab.1964.7-223

Bachman, G. F., \& Guerrero, L. K. (2006). Forgiveness, apology, and communicative responses to hurtful events. Communication Reports, 19, 45-56. doi: 10.1080/08934210600586357

Bagaric, M., \& Amarasekara, K. (2001). Feeling sorry? - Tell someone who cares: The irrelevance of remorse in sentencing. The Howard Journal of Crime and Justice, 40, 364-376. doi: 10.1111/1468-2311.00215

Baker, A. G., Steinwald, H., \& Bouton, M. E. (1991). Contextual conditioning and reinstatement of extinguished instrumental responding. The Quarterly Journal of Experimental Psychology, 43, 199-218.

Banks, R. K., \& Vogel-Sprott, M. (1965). Effect of delayed punishment on an immediately rewarded response in humans. Journal of Experimental Psychology, 70, 357-359. doi: 10.1037/h0022233

Bell, K. M., \& Naugle, A. E. (2005). Understanding stay/leave decisions in violent relationships: A behavior analytic approach. Behavior and Social Issues, 14, 21-45. doi: 10.5210/bsi.v14i1.119

Berkowitz, L. (1983). Aversively stimulated aggression: Some parallels and differences in research with animals and humans. American Psychologist, 38, 1135-1144. doi: 10.1037/0003-066X.38.11.1135

Berkowitz, L. (1993). Pain and aggression: Some findings and implications. Motivation and Emotion, 17, $277-293$. doi: $10.1007 / \mathrm{BF} 00992223$

Bibas, S., \& Bierschbach, R. A. (2004). Integrating remorse and apology into criminal procedure. The Yale Law Journal, 114, 85-148. doi: $\underline{10.2307 / 4135717}$ 


\section{TONEY \& HAYES}

Boren, J. J., Sidman, M., \& Herrnstein, R. J. (1959). Avoidance, escape, and extinction as functions of shock intensity. Journal of Comparative Psychology, 52, 420-425. doi: 10.1037/h0042727

Boroczi, G., Storms, L. H., \& Broen, W. E., Jr. (1964). Response suppression and recovery of responding at different deprivation levels as functions of intensity and duration of punishment. Journal of Comparative and Physiological Psychology, 58, 456-459. doi: 10.1037/h0045630

Bush, B. J. (2014). The overlooked function of punitive damages. Rutgers Law Journal, 44, 161-211.

Catania, A. C. (2007). Learning (4 $4^{\text {th }}$ ed.). Cornwall-on-Hudson: Sloan Publishing.

Chapman, G., \& Thomas, J. M. (2006). The five languages of apology: How to experience healing in your relationships. Chicago, IL: Northfield Publishing.

Clark, H. B., Rowbury, T., Baer, A. M., \& Baer, D. M. (1973). Timeout as a punishing stimulus in continuous and intermittent schedules. Journal of Applied Behavior Analysis, 6, 443-455. doi: 10.1901/jaba.1973.6-443

Cowdery, G. E., Iwata, B. A., \& Pace, G. M. (1990). Effects and side effects of DRO as treatment for self-injurious behavior. Journal of Applied Behavior Analysis, 23, 497-506. doi: 10.1901/jaba.1990.23-497

Darby, B. W., \& Schlenker, B. R. (1982). Children's reactions to apologies. Journal of Personality and Social Psychology, 43, 742-753. doi: 10.1037/0022-3514.43.4.742

Davis, J. R., \& Gold, G. J. (2011). An examination of emotional empathy, attributions of stability, and the link between perceived remorse and forgiveness. Personality and Individual Differences, 50, 392-397. doi: 10.1016/j.paid.2010.10.031

Dinsmoor, J. A. (1954). Punishment: I. The avoidance hypothesis. Psychological Review, 61, 34-46. doi: $10.1037 / \mathrm{h} 0062725$

Dracobly, J. D., \& Smith, R. G. (2012). Progressing from identification and functional analysis of precursor behavior to treatment of self-injurious behavior. Journal of Applied Behavior Analysis, 45, 361-374. doi: 10.1901/jaba.2012.45-361

Ebesu Hubbard, A. S., Hendrickson, B., Fehrenbach, K. S., \& Sur, J. (2013). Effects of timing and sincerity of an apology on satisfaction and changes in negative feelings during conflicts. Western Journal of Communication, 77, 305-322. doi: $10.1080 / 10570314.2013 .770160$

Eisler, R. M., Miller, P. M., \& Hersen, M. (1973). Components of assertive behavior. Journal of Clinical Psychology, 29, 295-299. doi: 10.1002/1097-4679(197307)29:3<295::AID-JCLP2270290305>3.0.CO;2-9

Fehr, R., \& Gelfand, M. J. (2009). But I said I was sorry! On the importance of matching apologies to victim selfconstruals. Academy of Management Annual Meeting Proceedings, 8, 1-6. doi: 10.5465/AMBPP.2009.44243706

Filby, Y., \& Appel, J. B. (1966). Variable-interval punishment during variable-interval reinforcement. Journal of the Experimental Analysis of Behavior, 9, 521-527. doi: 10.1901/jeab.1966.9-521

Friman, P. C., \& Poling, A. (1995). Making life easier with effort: Basic findings and applied research on response effort. Journal of Applied Behavior Analysis, 28, 583-590. doi: 10.1901/jaba.1995.28-583

Gewirtz, J. L., \& Baer, D. M. (1958). The effect of brief social deprivation on behaviors for a social reinforcer. The Journal of Abnormal and Social Psychology, 56, 49-56. doi: 10.1037/h0047188

Gottschalk, J. M., Libby, M. E., \& Graff, R. B. (2000). The effects of establishing operations on preference assessment outcomes. Journal of Applied Behavior Analysis, 33, 85-88. doi: 10.1901/jaba.2000.33-85

Groves, P. M., \& Thompson, R. F. (1970). Habituation: A dual-process theory. Psychological Review, 77, 419-450. doi: $10.1037 / \mathrm{h} 0029810$

Grow, L. L., Kelley, M. E., Roane, H. S., \& Shillingsburg, M. A. (2008). Utility of extinction-induced response variability for the selection of mands. Journal of Applied Behavior Analysis, 41, 15-24. doi: 10.1901/jaba.2008.41-15

Hantula, D. A. (1992). The basic importance of escalation. Journal of Applied Behavior Analysis, 25, 579-583. doi: 10.1901/jaba.1992.25-579

Hareli, S., \& Eisikovits, Z. (2006). The role of communicating social emotions accompanying apologies in forgiveness. Motivation and Emotion, 30, 189-197. doi: 10.1007/s11031-006-9025-X

Hayes, L. J. (1992). The psychological present. The Behavior Analyst, 15, 139-145. doi: 10.1007/BF03392596

Hayes, L. J. (1998). Remembering as a psychological event. Journal of Theoretical and Philosophical Psychology, 18, 135-143. doi: $10.1037 / \mathrm{h} 0091180$

Hayes, S. C. (2004). Rule-governed behavior: Cognition, contingencies, and instructional control. Reno, NV: Context Press.

Hebl, J. H., \& Enright, R. D. (1993). Forgiveness as a psychotherapeutic goal with elderly females. Psychotherapy, 30, 658-667. doi: $\underline{10.1037 / 0033-3204.30 .4 .658}$ 


\section{APOLOGIES, FORGIVENESS, AND INTERPERSONAL CONFLICT}

Heimberg, R. G., Montgomery, D., Madsen, C. H., Jr., \& Heimberg, J. S. (1977). Assertion training: A review of the literature. Behavior Therapy, 8, 953-971. doi: 10.1016/S0005-7894(77)80165-2

Hollandsworth, J. G., Jr., \& Cooley, M. L. (1978). Provoking anger and gaining compliance with assertive versus aggressive responses. Behavior Therapy, 9, 640-646. doi: 10.1016/S0005-7894(78)80140-3

Johnston, J. M. (1972). Punishment of human behavior. American Psychologist, 27, 1033-1054. doi: $10.1037 / \mathrm{h} 0033887$

Jones, W. H., Moore, D. S., Schratter, A., \& Negel, L. A. (2001). Interpersonal transgressions and betrayals. In R. M. Kowalski, Behaving badly: Aversive behaviors in interpersonal relationships (pp. 233-256). Washington, DC: American Psychological Association. doi: 10.1037/10365-009

Kador, J. (2009). Effective apology: Mending fences, building bridges, and restoring trust. San Francisco, CA: Berrett-Koehler Publishers, Inc.

Kazdin, A. E., \& Klock, J. (1973). The effect of nonverbal teacher approval on student attentive behavior. Journal of Applied Behavior Analysis, 6, 643-654. doi: 10.1901/jaba.1973.6-643

Keller, F. S., \& Schoenfeld, W. N. (1950). Principles of psychology. New York, NY: Appleton-Century-Crofts.

Kelly, J. F., \& Hake, D. F. (1970). An extinction-induced increase in an aggressive response with humans. Journal of the Experimental Analysis of Behavior, 14, 153-164. doi: 10.1901/jeab.1970.14-153

Kinloch, J. M., Foster, T. M., \& McEwan, J. S. A. (2009). Extinction-induced variability in human behavior. The Psychological Record, 59, 347-370. doi: 10.1007/BF03395669

Kowalski, R. M. (2001). Behaving badly: Aversive behaviors in interpersonal relationships. Washington, DC: American Psychological Association. doi: 10.1037/10365-000

Lattal, K. A. (2010). Delayed reinforcement of operant behavior. Journal of the Experimental Analysis of Behavior, 93, 129-139. doi: $10.1901 /$ jeab.2010.93-129

Lavigna, G. W., \& Donnellan, A. M. (1986). Alternatives to punishment: Solving behavior problems with nonaversive strategies. New York, NY: Irvington Publishers, Inc.

Layng, T. J. (2017). Private emotions as contingency descriptors: Emotions, emotional behavior, and their evolution. European Journal of Behavior Analysis, 1-12. doi: 10.1080/15021149.2017.1304875

Lazare, A. (2004). On apology. New York, NY: Oxford University Press.

Lazare, A. (2006). Apology in medical practice: An emerging clinical skill. Journal of the American Medical Association, 296, 1401-1404. doi: 10.1001/jama.296.11.1401

Leary, M. R., Springer, C., Negel, L., Ansell, E., \& Evans, K. (1998). The causes, phenomenology, and consequences of hurt feelings. Journal of Personality and Social Psychology, 74, 1225-1237. doi: 10.1037/0022-3514.74.5.1225

Lerman, D. C., Iwata, B. A., Shore, B. A., \& DeLeon, I. G. (1997). Effects of intermittent punishment on selfinjurious behavior: An evaluation of schedule thinning. Journal of Applied Behavior Analysis, 30, 187-201. doi: 10.1901/jaba.1997.30-187

Lewon, M., \& Hayes, L. J. (2014). Toward an analysis of emotions as products of motivating operations. The Psychological Record, 64, 813-825. doi: 10.1007/s40732-014-0046-7

Logue, A. W., \& Pena-Correal, T. E. (1985). The effect of food deprivation on self-control. Behavioural Processes, 10, 355-368. doi: 10.1016/0376-6357(85)90036-1

Maier, S. F., \& Seligman, M. E. P. (1976). Learned helplessness: Theory and evidence. Journal of Experimental Psychology: General, 105, 3-46. doi: 10.1037/0096-3445.105.1.3

Malott, R. W., \& Shane, J. T. (2016). Principles of behavior ( $7^{\text {th }}$ ed.). New York, NY: Routledge.

Marchand, J. F., \& Hock, E. (2000). Avoidance and attacking conflict-resolution strategies among married couples: Relations to depressive symptoms and marital satisfaction. Family Relations, 49, 201-206. doi: 10.1111/j.17413729.2000.00201.x

Marcus, B. A., \& Vollmer, T. R. (1996). Combining noncontingent reinforcement and differential reinforcement schedules as treatment for aberrant behavior. Journal of Applied Behavior Analysis, 29, 43-51. doi: 10.1901/jaba.1996.29-43

McCullough, M. E., Bellah, C. G., Kilpatrick, S. D., Johnson, J. L. (2001). Vengefulness: Relationships with forgiveness, rumination, well-being, and the big five. Personality and Social Psychology Bulletin, 27, 601-610. doi: $\underline{10.1177 / 0146167201275008}$

McCullough, M. E., Rachal, K. C., Sandage, S. J., Worthington, E. L., Jr., Brown, S. W., \& Hight, T. L. (1998). Interpersonal forgiving in close relationships: II. Theoretical elaboration and measurement. Journal of Personality and Social Psychology, 75, 1586-1603. doi: 10.1037/0022-3514.75.6.1586 


\section{TONEY \& HAYES}

McGill, P. (1999). Establishing operations: Implications for the assessment, treatment, and prevention of problem behavior. Journal of Applied Behavior Analysis, 32, 393-418. doi: 10.1901/jaba.1999.32-393

McMillan, D. E. (1967). A comparison of the punishing effects of response-produced shock and response-produced time out. Journal of the Experimental Analysis of Behavior, 10, 439-449. doi: 10.1901/jeab.1967.10-439

McNulty, J. K. (2011). The dark side of forgiveness: The tendency to forgive predicts continued psychological and physical aggression in marriage. Personality and Social Psychology Bulletin, 37, 770-783. doi: $10.1177 / 0146167211407077$

Michael, J. L. (2000). Implications and refinements of the establishing operation concept. Journal of Applied Behavior Analysis, 33, 401-410. doi: 10.1901/jaba.2000.33-401

Michael, J. L. (2004). Concepts and principles of behavior analysis. Kalamazoo, MI: Association for Behavior Analysis International.

Morgan, D. L., \& Lee, K. (1996). Extinction-induced response variability in humans. The Psychological Record, 46, 145-159. doi: $10.1007 / \mathrm{BF} 03395168$

Mushkambaryan, A. (2012). Nonverbal expression of emotions in conflict escalation. World Academy of Science, Engineering and Technology, International Science Index 66, International Journal of Social, Behavioral, Educational, Economic, Business and Industrial Engineering, 6, 1651-1659.

Myers, D. L. (1995). Eliminating the battering of women by men: Some considerations for behavior analysis. Journal of Applied Behavior Analysis, 28, 493-507. doi: 10.1901/jaba.1995.28-493

Najdowski, A. C., Wallace, M. D., Ellsworth, C. L., MacAleese, A. N., \& Cleveland, J. M. (2008). Functional analyses and treatment of precursor behavior. Journal of Applied Behavior Analysis, 41, 97-105. doi: 10.1901/jaba.2008.41-97

Noller, P. (1980). Misunderstandings in marital communication: A study of couples' nonverbal communication. Journal of Personality and Social Psychology, 39, 1135-1148. doi: 10.1037/h0077716

Noreen, S., Bierman, R. N., \& MacLeod, M. D. (2014). Forgiving you is hard, but forgetting seems easy: Can forgiveness facilitate forgetting? Psychological Science, 25, 1295-1302. doi: $10.1177 / 0956797614531602$

Ohbuchi, K., Kameda, M., \& Agarie, N. (1989). Apology as aggression control: Its role in mediating appraisal of and response to harm. Journal of Personality and Social Psychology, 56, 219-227. doi: 10.1037/0022$\underline{3514.56 .2 .219}$

Ollendick, T. H., \& Matson, J. L. (1978). Overcorrection: An overview. Behavior Therapy, 9, 830-842. doi: $\underline{10.1016 / \mathrm{S} 0005-7894(78) 80014-8}$

Piazza, C. C., Moes, D. R., \& Fisher, W. W. (1996). Differential reinforcement of alternative behavior and demand fading in the treatment of escape-maintained destructive behavior. Journal of Applied Behavior Analysis, 29, 569-572. doi: $10.1901 / \mathrm{jaba} .1996 .29-569$

Rakos, R. F. (1991). Assertive behavior: Theory, research, and training. New York, NY: Routledge.

Retzinger, S. M. (1991). Shame, anger, and conflict: Case study of emotional violence. Journal of Family Violence, 6, 37-59. doi: 10.1007/BF00978525

Roane, H. S., Fisher, W. W., Sgro, G. M., Falcomata, T. S., \& Pabico, R. R. (2004). An alternative method of thinning reinforcer delivery during differential reinforcement. Journal of Applied Behavior Analysis, 37, $213-$ 218. doi: $10.1901 /$ jaba.2004.37-213

Schumann, K. (2012). Does love mean never having to say you're sorry? Associations between relationship satisfaction, perceived apology sincerity, and forgiveness. Journal of Social and Personal Relationships, 29, 114. doi: $10.1177 / 0265407512448277$

Serber, M. (1972). Teaching the nonverbal components of assertive training. Journal of Behavior Therapy and Experimental Psychiatry, 3, 179-183. doi: 10.1016/0005-7916(72)90070-5

Shepard, R. N. (1958). Stimulus and response generalization: Deduction of the generalization gradient from a trace model. Psychological Review, 65, 242-256. doi: 10.1037/h0043083

Sidelinger, R. J., Frisby, B. N., \& McMullen, A. L. (2009). The decision to forgive: Sex, gender, and the likelihood to forgive partner transgressions. Communication Studies, 60, 164-179. doi: $\underline{10.1080 / 10510970902834890}$

Sidman, M. (1953). Avoidance conditioning with brief shock and no exteroceptive warning signal. Science, 118, 157-158. doi: $10.1126 /$ science.118.3058.157

Sidman, M. (1962). Classical avoidance without a warning stimulus. Journal of the Experimental Analysis of Behavior, 5, 97-104. doi: 10.1901/jeab.1962.5-97

Sidman, M. (1989). Coercion and its fallout. Boston, MA: Authors Cooperative.

Sidman, M., \& Boren, J. J. (1957). A comparison of two types of warning stimulus in an avoidance situation. Journal of Comparative and Physiological Psychology, 50, 282-287. doi: 10.1037/h0046474 


\section{APOLOGIES, FORGIVENESS, AND INTERPERSONAL CONFLICT}

Simpson, S. Q. (2005). Apology: The importance and power of saying "I'm sorry." Gaylord, MI: Balcony Publications.

Skinner, B. F. (1953). Science and human behavior. New York, NY: The Free Press.

Skinner, B. F. (1957). Verbal behavior. Cambridge, MA: B. F. Skinner Foundation. doi: $10.1037 / 11256-000$

Skinner, B. F. (1969). Contingencies of reinforcement: A theoretical analysis. New York, NY: Appleton-CenturyCrofts.

Skinner, B. F. (1971). Beyond freedom and dignity. New York, NY: Knopf, Inc.

Skinner, B. F. (1974). About behaviorism. New York, NY: Knopf, Inc.

Skinner, B. F. (1975). The steep and thorny way to a science of behavior. American Psychologist, 30, 42-49. doi: 10.1037/0003-066X.30.1.42

Skinner, B. F. (1978). Reflections on behaviorism and society. Englewood Cliffs, NJ: Prentice-Hall, Inc.

Skinner, B. F. (1981). Selection by consequences. Science, 213, 501-504. doi: 10.1126/science. 7244649

Skinner, B. F. (1985). News from nowhere, 1984. The Behavior Analyst, 8, 5-14. doi: $\underline{10.1007 / \mathrm{BF} 03391908}$

Skinner, B. F. (1986). The evolution of verbal behavior. Journal of the Experimental Analysis of Behavior, 45, 115122. doi: $10.1901 /$ jeab.1986.45-115

Szablowinski, Z. (2012). Apology with and without a request for forgiveness. The Heythrop Journal, 53, 731-741. doi: $10.1111 / \mathrm{j} .1468-2265.2011 .00720 . \mathrm{x}$

Thomas, J. R. (1968). Fixed-ratio punishment by timeout of concurrent variable-interval behavior. Journal of the Experimental Analysis of Behavior, 11, 609-616. doi: 10.1901/jeab.1968.11-609

Thomas, R. L., \& Millar, M. G. (2008). The impact of failing to give an apology and the need-for-cognition on anger. Current Psychology, 27, 126-134. doi: 10.1007/s12144-008-9025-y

Tudor, S. K. (2008). Why should remorse be a mitigating factor in sentencing? Criminal Law and Philosophy, 2, 241-257. doi: $10.1007 / \mathrm{s} 11572-007-9044-\mathrm{z}$

Ulrich, R. E., \& Azrin, N. H. (1962). Reflexive fighting in response to aversive stimulation. Journal of the Experimental Analysis of Behavior, 5, 511-520. doi: 10.1901/jeab.1962.5-511

Ulrich, R. E., Holz, W. C., \& Azrin, N. H. (1964). Stimulus control of avoidance behavior. Journal of the Experimental Analysis of Behavior, 7, 129-133. doi: 10.1901/jeab.1964.7-129

Ulrich, R. E., Hutchinson, R. R., \& Azrin, N. H. (1965). Pain-elicited aggression. The Psychological Record, 15, 111-126.

Vernon, W., \& Ulrich, R. (1966). Classical conditioning of pain-elicited aggression. Science, 152, 668-669. doi: $10.1126 /$ science. 152.3722 .668

Vollmer, T. R., \& Iwata, B. A. (1991). Establishing operations and reinforcement effects. Journal of Applied Behavior Analysis, 24, 279-291. doi: 10.1901/jaba.1991.24-279

Ward, B. H. (2006). Sentencing without remorse. Loyola University of Chicago Law Journal, 38, 131-167.

White, G. D., Nielsen, G., \& Johnson, S. M. (1972). Timeout duration and the suppression of deviant behavior in children. Journal of Applied Behavior Analysis, 5, 111-120. doi: 10.1901/jaba.1972.5-111

Witvliet, C. V. O., Ludwig, T. E., \& Bauer, D. J. (2002). Please forgive me: Transgressors' emotions and physiology during imagery of seeking forgiveness and victim responses. Journal of Psychology and Christianity, 21, 219233.

Wooten, D. B. (2009). Say the right thing: Apologies, reputability, and punishment. Journal of Consumer Psychology, 19, 225-235. doi: 10.1016/j.jcps.2009.02.017

Zechmeister, J. S., Garcia, S., Romero, C., \& Vas, S. N. (2004). Don't apologize unless you mean it: A laboratory investigation of forgiveness and retaliation. Journal of Social and Clinical Psychology, 23, 532-564. doi:

10.1521/jscp.23.4.532.40309 